\title{
PENERAPAN KONSEP ENJOYFULL LEARNING MENGGUNAKAN MULTIMEDIA UNTUK MENINGKATKAN HASIL BELAJAR KIMIA PADA MATERI HUKUM-HUKUM DASAR KIMIA DAN STOIKIOMETRI (PENELITIAN TINDAKAN KELAS DI MAN 1 GROBOGAN)
}

\author{
Fujiama Diapoldo Silalahi' ${ }^{1}$ Moh Muthohir ${ }^{2}$, Mukhoyyarotul Jannah ${ }^{3}$
}

${ }^{1}$ STEKOM, Fujiama@ stekom.ac.id

${ }^{2}$ STEKOM, muthohir@stekom.ac.id

${ }^{3}$ MAN 1 Grobogan, nanajannah9893@gmail.com

1,2 Jl. Majapahit 605, Semarang, telp/fax : 024-6717201-02

${ }^{3} \mathrm{Jl}$. Diponegoro No. 22 Grobogan, telp/fax : 0292-421234

\section{ARTICLE INFO}

Article history:

Received 30 Mei 2020

Received in revised form 2 Juni 2020

Accepted 10 Juli 2020

Available online 17 Juli 2020
ABSTRACT

This research, in general, aims to improve the learning outcomes of class X MIPA 4 students of MAN 1 Grobogan in the 2018/2019 academic year by implementing multimedia learning. And specifically it aims to make students able to achieve the learning objectives by producing a minimum KKM score of 70 and at least $80 \%$ of the total students are able to reach this minimum limit. The research method used in this research is the Classroom Action Research Method or better known as the Classroom Action Research (PTK) method. The PTK method is a process of assessing learning problems in the classroom through self-reflection in an effort to solve these problems by taking planned actions in real situations and analyzing any effects of these treatments. The results of research conducted on class X MIPA 4 MAN 1 Grobogan, the application of multimedia presentation learning media on the basic laws of chemistry and stoichiometry with the concept of enjoyful learning can improve student learning outcomes. That the application of multimedia presentation learning media can improve student learning outcomes in chemistry, especially in the material of the basic laws of chemistry and stoichiometry

Keywords: Classroom Action Research Method, multimedia presentation learning, stoichiometry

\section{Pendahuluan}

Pendidikan merupakan kebutuhan dasar manusia untuk menjalani kehidupan. Pendidikan juga menjadi salah satu faktor penting seseorang untuk dapat meraih cita-cita dan mendapatkan kebahagiaan melalui ilmu yang dimilikinya. Melalui pendidikan, manusia ditempa menjadi seorang ilmuwan yang dapat hidup bermasyarakat. Disadari atau tidak, pendidikan merupakan upaya terencana dalam proses pembimbingan 
dan pembelajaran bagi individu agar berkembang dan tumbuh menjadi manusia mandiri, bertanggungjawab, kreatif, berilmu, sehat dan berakhlak mulia baik dilihat dari aspek jasmani maupun ruhani [1]

Perkembangan teknologi dan pengetahuan saat ini berdampak pada dunia pendidikan yang meliputi perubahan manajemen kurikulum, tenaga kependidikan, strategi dan metode pendidikan [2]. Oleh karena itu pendidikan merupakan salah satu aspek yang tidak dapat lepas dari pemanfaatan teknologi terbarukan, sehingga guru harus berupaya untuk selalu berinovasi dalam kegiatan belajar-mengajar.

Ilmu kimia merupakan suatu cabang ilmu yang mempelajari tentang struktur, materi dan perubahanperubahan yang dialami materi dalam proses-proses alamiah maupun dalam eksperimen yang direncanakan [3]. Pelajaran kimia di kelas $X$ banyak berisi konsep-konsep yang cukup sulit untuk dipahami siswa, karena menyangkut reaksi-reaksi kimia dan hitungan-hitungan serta menyangkut konsep-konsep yang bersifat abstrak sehingga untuk memahaminya harus adanya rasa ingin tahu untuk bertanya kepada guru dan kerjasama antarsiswa untuk belajar bersama memahami dan saling bertanya serta saling menjelaskan satu dengan yang lain [4]. Dalam proses pembelajaran kimia, khususnya pada materi hukum dasar kimia dan STOIKIOMETRI, terkadang siswa merasa jenuh dan kurang memiliki minat pada pelajaran kimia, sehingga suasana kelas cenderung pasif, sedikit sekali siswa yang bertanya pada guru meskipun materi yang diajarkan belum dapat dipahami. Kejenuhan siswa ini menjadi salah satu faktor rendahnya hasil belajar siswa dikarenakan beberapa siswa tidak dapat mencapai batas KKM yang ditentukan.

Hasil analisis guru MGMP mata pelajaran kimia di MAN 1 Grobogan, ternyata rendahnya hasil belajar siswa tersebut disebabkan pada umumnya siswa mengalami kesulitan dalam menyelesaikan permasalahan yang menyangkut hukum-hukum dasar kimia dan stoikiometri, akibat rendahnya pemahaman konsepkonsep kimia dan kurangnya minat siswa terhadap pelajaran kimia. Oleh sebab itu, diperlukan suatu usaha untuk mengoptimalkan pembelajaran kimia di kelas dengan menerapkan pendekatan dan metode yang tepat.

Menyadari fenomena yang demikian, maka guru sebagai pendidik perlu menerapkan metode yang lebih menarik dalam menyampaikan materi Kimia. Salah satunya dengan menggunakan media pembelajaran. Metode inilah yang kemudian dapat dimanfaatkan dalam usaha pengembangan media pembelajaran siswa agar lebih menarik dan dapat merangsang keinginan anak untuk belajar kimia.

Paradigma pembelajaran telah berkembang dengan berbagai macam teori. Diantara berbagai konsep tersebut, salah satunya adalah konsep enjoyful learning. Konsep ini menekankan pembelajaran yang didukung oleh lingkungan yang menyenangkan yang dapat meningkatkan semangat belajar (enjoyful learning). Konsep enjoyful learning merupakan sistem pembelajaran yang berusaha membangkitkan minat, adanya keterlibatan penuh dan terciptanya makna, pemahaman, nilai yang membahagiakan dari siswa [5].

Penelitian ini, secara umum bertujuan untuk meningkatkan hasil belajar siswa kelas X MIPA 4 MAN 1 Grobogan tahun ajaran 2018/2019 dengan menerapkan multimedia pembelajaran. Dan secara khusus bertujuan agar siswa mampu mencapai tujuan pembelajaran dengan menghasilkan nilai minimal KKM 70 dan sekurang-kurangnya $80 \%$ dari jumlah siswa mampu mencapai batas minimal tersebut.

\section{Kajian Penelitian yang Relevan}

Berikut kajian-kajian relevan yang penulis catut dari hasil penelitian terdahulu yang berhubungan dengan penelitian yang sedang penulis kaji guna mendukung penyusunan penelitian tindakan kelas ini:

Efektifitas Penerapan Metode Enjoyfull Learning dalam Peningkatan Minat Belajar Siswa Kelas X SMA Negeri 1 Bolo Kab. Bima [5], Model Joyfull Learning dalam Meningkatkan Keterampilan Menulis Naskah Drama Siswa Kelas VIII [6], Penerapan Model Pembelajaran Inkuiri Terbimbing dilengkapi LKS untuk Meningkatkan Keterampilan Proses Sains dan Prestasi Belajar pada Materi Pokok Hukum Dasar Kimia Siswa Kelas X MIA 4 SMA N 1 Karanganyar Tahun pelajaran 2014/2015 [7]

\section{Kajian Teoritis}

\section{a. Multimedia Pembelajaran}

Media pembelajaran sebagai media pendidikan, yakni alat, metode, dan teknik yang digunakan dalam rangka lebih mengefektifkan komunikasi dan interaksi antara guru dan siswa dalam proses pendidikan dan pengajaran di sekolah. Media pembelajaran dapat diartikan dengan sebutan media instruksional edukatif. Artinya, Media instruksional edukatif berfungsi sebagai sarana komunikasi dalam proses belajar mengajar yang berupa perangkat keras maupun perangkat lunak untuk mencapai proses dan hasil instruksional secara efektif dan efisien, serta tujuan instruksional dapat dicapaidengan mudah. Media instruksional 
edukatif adalah media yang digunakan dalam proses intruksional (belajar mengajar) untuk mempermudah pencapaian tujuan instruksional yang lebih efektif dan memiliki sifat mendidik [8].

\section{b. Konsep Enjoyfull Learning}

Enjoyful Learning merupakan metode pembelajaran yang melibatkan rasa senang, bahagia, dan nyaman dari pihak-pihak yang sedang berada dalam proses belajar mengajar. Di sini terdapat keterikatan cinta dan kasih sayang antara guru dan peserta didik maupun antar peserta didik. Keterikatan hati di dalam proses belajar mengajar akan membuat masing-masing pihak berusaha memberikan yang terbaik untuk menyenangkan pihak lain. Guru dengan semangat menggebu-gebu akan berusaha optimal memimpin kelas dengan cara yang paling menarik, sedangkan peserta dengan antusias dan berlomba-lomba ikut aktif ambil bagian dalam setiap kegiatan. Dengan demikian, enJoyful Learning menjadi sarana yang membuat guru maupun peserta didikmenjadi betah menjalani sesi demi sesi pelajaran sehingga hasilnya akan maksimal [9].

Jadi dapat dikatakan bahwa prinsip dasar dari konsep enjoyful learning adalah menimbulkan antusiasme, kemandirian dan motivasi siswa sehingga anak dapat menikmati pelajaran yang diberikan.

\section{c. Hasil Belajar}

Hasil belajar sering kali digunakan sebagai ukuran untuk mengetahui seberapa jauh seseorang menguasai bahan yang sudah diajarkan. Hasil belajar dapat dijelaskan dengan memahami dua kata yang membentuknya, yaitu "hasil" dan "belajar". Pengertian hasil menunjukan pada suatu perolehan akibat dilakukannya suatu aktivitas atau proses yang mengakibatkan berubahannya input secara fungsional, sedangkan belajar dilakukannya untuk mengusahakan adanya perubahan perilaku pada individu yang belajar. Hasil belajar adalah bukti keberhasilan yang telah dicapai siswa dimana setiap kegiatan dapat menimbulkan suatu perubahan yang khas, dalam hal ini hasil belajar meliputi keaktifan, keterampilan proses, motivasi, dan prestasi belajar. Jadi hasil belajar merupakan hasil yang dicapai dalam bentuk angka atau skor setelah diberikan tes hasil belajar kepada siswa dalam waktu tertentu [10].

\section{Kerangka Berfikir}

Berikut kerangka berfikir dalam penelitian ini:

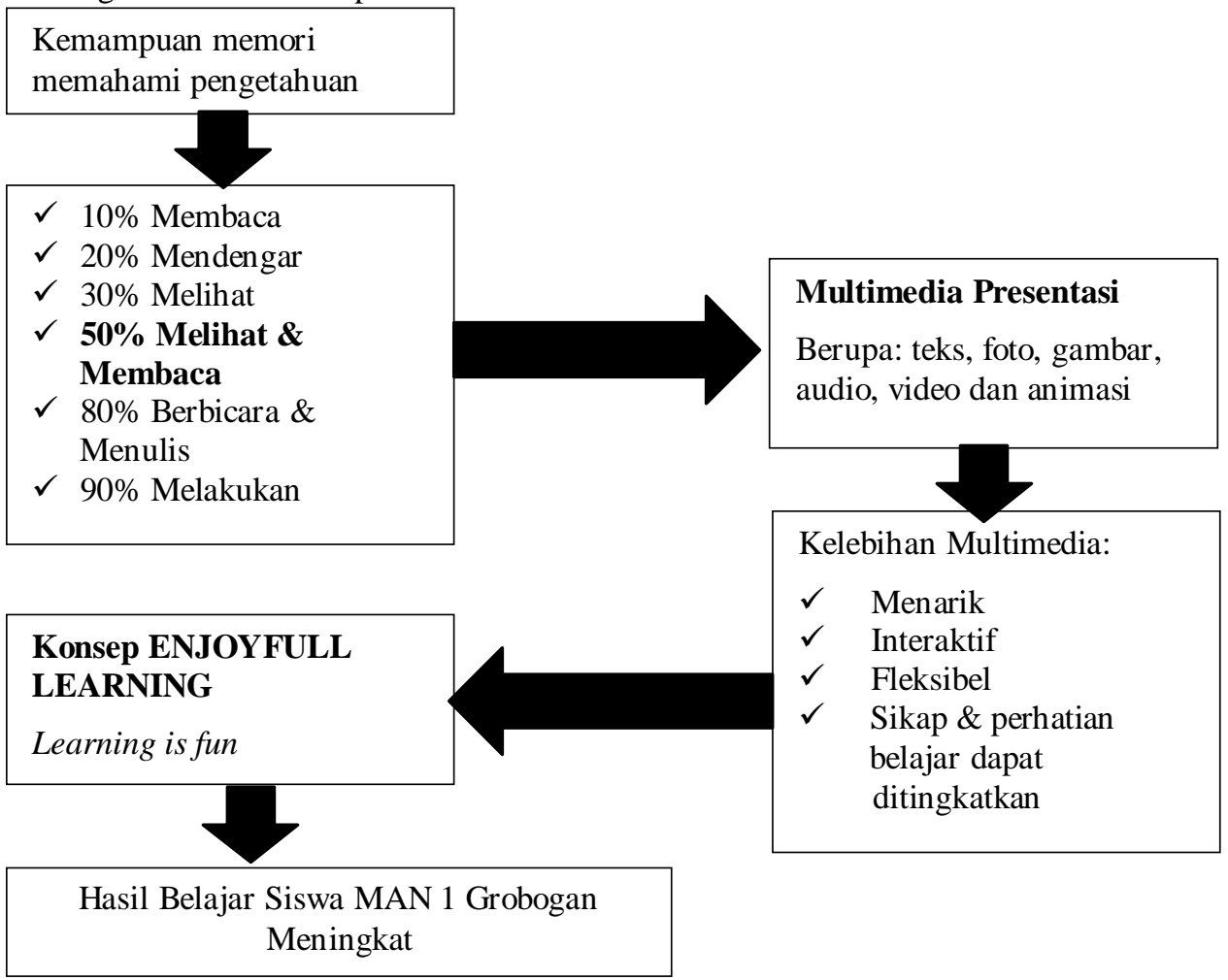

Gambar 1. Kerangka Berfikir

JURNAL ILMIAH KOMPUTER GRAFIS Vol. 13, No. 1, Juli $2020: 28$ - 38 


\section{Metode Penelitian}

Metode penelitian yang digunakan pada penelitian ini adalah Classroom Action Reasearch Method atau lebih dikenal dengan metode penelitian tindakan kelas (PTK). Metode PTK ini merupakan proses pengkajian masalah pembelajaran di dalam kelas melalui refleksi diri dalam upaya memecahkan masalah tersebut dengan cara melakukan berbai tindakan yang terencana dalam situasi nyata serta menganalisis setiap pengaruh dari perlakuan tersebut [11]. Kegiatan PTK memiliki beberapa siklus, setiap siklus memiliki beberapa tahapan yaitu perencanaan, tindakan, pengamatan dan refleksi[12].

\section{Desain Siklus PTK}

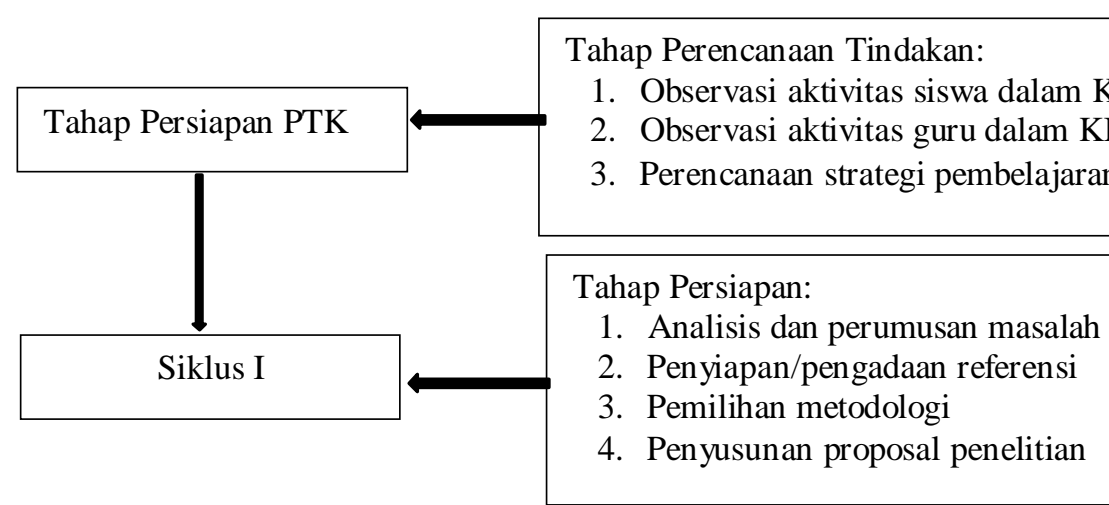

Tahap Pelaksanaan Tindakan dan observasi:

1. Pengelolaan sarana penunjang KBM

2. Pelaksanaan KBM

3. Pelaksanaan Observasi

Tahap Evaluasi Tindakan:

1. Evaluasi $\mathrm{KBM}$ oleh peneliti

2. Evaluasi pencapaian hasil belajar siswa (Tes 1)

Tahap Analisis dan Refleksi:

1. Analisis dan refleksi terhadap hasil observasi

2. Analisis dan refleksi terhadap hasil tes 1

Tahap perencanaan tindakan:

1. Revisi KBM siklus I

2. Revisi sarana Penunjang KBM

Siklus II

Tahap Pelaksanaan Tindakan dan observasi:

1. Pengelolaan sarana penunjang KBM

2. Pelaksanaan KBM

3. Pelaksanaan Observasi

Tahap Evaluasi Tindakan:

1. Evaluasi KBM oleh peneliti

2. Evaluasi pencapaian hasil belajar siswa (Tes 2)

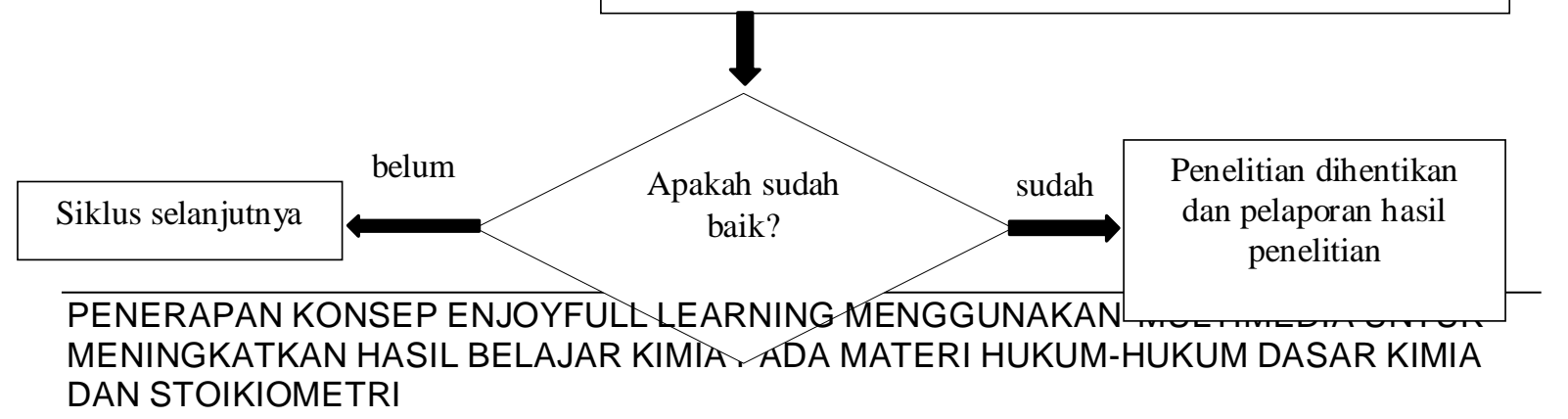


Gambar 2. Desain siklus PTK

\section{Subyek yang terlibat dalam penelitian}

Subjek penelitian dalam penelitian ini adalah siswa MAN 1 Grobogan, kelas X MIPA 4 Semester Genap tahun ajaran 2018/2019

\section{Tahapan Intervensi Tindakan}

Penelitian tindakan kelas ini dilaksanakan dalam beberapa siklus pada materi hukum-hukum dasar kimia dan stoikiometri. Hal ini dimaksudkan untuk melihat peningkatan hasil belajar siswa pada setiap siklus yang telah diberikan tindakan. Bila pada siklus I terdapat perkembangan, maka kegiatan penelitian pada siklus II diarahkan pada kegiatan perbaikan dan penyempurnaan terhadap hal-hal yang dianggap kurang pada siklus I

Tabel 1. Tahapan intervensi tindakan

\begin{tabular}{|c|c|c|}
\hline \multicolumn{2}{|c|}{ Kegiatan pendahuluan } & $\begin{array}{l}\text { a. Menentukan sekolah yang dijadikan } \\
\text { subjek penelitian } \\
\text { b. Wawancara dan konsultasi dengan } \\
\text { guru bidang studi kimia tempat } \\
\text { dilaksanakannya penelitian } \\
\text { c. Melaksanakan observasi proses } \\
\text { pembelajaran di kelas yang akan } \\
\text { diteliti } \\
\text { d. Melaksanakan wawancara kepada guru } \\
\text { dan siswa mengenai pembelajaran } \\
\text { kimia } \\
\text { e. Menganalisis permasalahan dari hasil } \\
\text { observasi dan wawancara } \\
\text { f. Merencanakan tindakan yang dapat } \\
\text { didikan solisi permasalahan yang ada }\end{array}$ \\
\hline \multicolumn{3}{|c|}{ Siklus I } \\
\hline 1 & Perencanaan & $\begin{array}{l}\text { a. Membuat rencana pembelajaran } \\
\text { sesuai dengan penggunaan media } \\
\text { multimedia presentasi } \\
\text { b. Menyiapkan instrumen (tes kognitif, } \\
\text { lembar observasi, pedoman } \\
\text { wawancara dan angket) }\end{array}$ \\
\hline 2 & Tindakan & $\begin{array}{l}\text { Melaksanakan langkah-langkah sesuai } \\
\text { rencana pembelajaran yang telah disusun, } \\
\text { diantaranya: } \\
\text { a. Melaksanakan pembelajaran kimia } \\
\text { sesuai dengan apa yang direncanakan } \\
\text { b. Ketika proses pembelajaran } \\
\text { berlangsung, dilakukan observasi } \\
\text { mengenai aktivitas guru dan siswa } \\
\text { c. Melakukan tes akhir untuk mengetahui } \\
\text { hasil belajar siswa sesudah diterapkan } \\
\text { pembelajaran dengan multimedia } \\
\text { presentasi }\end{array}$ \\
\hline 3 & Pengamatan & $\begin{array}{l}\text { a. Melakukan observasi dengan } \\
\text { menggunakan format observasi }\end{array}$ \\
\hline
\end{tabular}

JURNAL ILMIAH KOMPUTER GRAFIS Vol. 13, No. 1, Juli 2020 : $28-38$ 


\begin{tabular}{|c|c|c|}
\hline & & $\begin{array}{l}\text { b. Menilai hasil tindakan berdasarkan } \\
\text { format }\end{array}$ \\
\hline 4 & Refleksi & $\begin{array}{l}\text { a. Mengumpulkan data hasil pengamatan } \\
\text { dan menganalisis data yang diperoleh } \\
\text { untuk memperbaiki dan } \\
\text { menyempurnakan tindakan pada siklus } \\
\text { selanjutnya. } \\
\text { b. Menganalisis temuan saat melakukan } \\
\text { pengamatan proses pembelajaran yang } \\
\text { telah dilakukan } \\
\text { c. Menganalisis kelemahan dan } \\
\text { keberhasilan dari proses pembelajaran } \\
\text { yang berlangsung untuk } \\
\text { mempertimbangkan langkah } \\
\text { selanjutnya. }\end{array}$ \\
\hline \multicolumn{3}{|c|}{ Siklus II dan seterusnya } \\
\hline
\end{tabular}

\section{Hasil Intervensi Tindakah yang Diharapkan}

Tingkat keberhasilan setiap siklus adalah adanya peningkatan hasil belajar siswa yang dinyatakan dalam bentuk kualitatif dan kuantitatif. Data kualitatif dinyatakan dengan menggunakan analisis yang bersifat naratif, sedangkan data kuantitatif dinyatakan dengan angka rata-rata perolehan nilai siswa. Jika nilai ratarata siswa mencapai 70 dan sebanyak $80 \%$ siswa sudah mendapat nilai 70, maka penelitian dapat dikatakan berhasil. Apabila target tersebut belum tercapai perlu dilakukan refleksi ulang untuk melakukan tindakan selanjutnya, yaitu dengan mengobservasi kembali. Hal ini dilakukan berulang-ulang sampai target yang ditentukan tercapai atau sampai titik jenuh siswa.

\section{Data dan Sumber Data}

Data yang diperoleh berupa nilai tes hasil belajar siswa yang mencakup penguasaan materi hukum-hukum dasar kimia dan stoikiometri serta respon siswa terhadap multimedia presentasi yang diberikan. Di bawah ini adalah data dan sumber data yang dibutuhkan dalam penelitian ini:

Tabel 2. Data dan sumber data penelitian

\begin{tabular}{|l|l|l|l|}
\hline No & \multicolumn{1}{|c|}{ Data } & \multicolumn{1}{|c|}{ Sumber Data } & \multicolumn{1}{|c|}{$\begin{array}{c}\text { Instrumen yang } \\
\text { digunakan }\end{array}$} \\
\hline 1 & $\begin{array}{l}\text { Aktivitas yang dilakukan selama proses } \\
\text { pembelajaran }\end{array}$ & $\begin{array}{l}\text { Siswa kelas X MIPA 4 } \\
\text { dan guru kimia }\end{array}$ & Lembar observasi \\
\hline 2 & Nilai tes hasil belajar pada setiap siklus & Siswa kelas X MIPA 4 & Tes kognitif \\
\hline 3 & $\begin{array}{l}\text { Respon siswa terhadap media } \\
\text { pembelajaran multimedia presentasi }\end{array}$ & Siswa kelas X MIPA 4 & $\begin{array}{l}\text { Angket respon } \\
\text { siswa }\end{array}$ \\
\hline 4 & $\begin{array}{l}\text { Pendapat siswa selama mengikuti } \\
\text { proses pembelajaran }\end{array}$ & Siswa kelas X MIPA 4 & Lembar wawancara \\
\hline
\end{tabular}

\section{Analisis Data dan Intrepetasi Hasil Analisis}

Sebelum melakukan analisis data, peneliti memeriksa kembali kelengkapan data dari berbagai sumber. Kemudian analisis data dilakukan pada semua data yang sudah terkumpul, yaitu berupa hasil wawancara, hasil angket, hasil observasi, hasil tes siswa dan catatan komentar observer pada lembar observasi. Semua data dianalisis dengan menggunakan analisis deskriptif.

Untuk menganalisis tes hasil belajar siswa digunakan langkah-langkah sebagai berikut:

a. Menentukan Mean atau rata-rata hasil belajar siswa

$\bar{X}=\frac{\sum_{i} X_{i}}{n}$

b. Menentukan persentase ketuntasan kelas 


\section{$\%$ Nilai $=\frac{\text { jumlah siswa yang mendapat nilai } \geqq 70}{70} \times 100 \%$}

Untuk menganalisis setiap indikator aktivitas siswa, aktivitas guru dan angket digunakan teknik analisis secara deskriptif dengan rumus sebagai berikut:

$$
\begin{aligned}
& P=\frac{f}{g} x 100 \% \\
& \text { Keterangan: } \\
& \mathrm{P} \quad \text { : persentase aktivitas belajar } \\
& \text { f : frekuensi siswa yang melakukan indikator aktivitas belajar } \\
& \text { s : jumlah siswa yang hadir }
\end{aligned}
$$

\section{Indikator Keberhasilan}

Penelitian ini dikatakan berhasil atau siswa mengalami peningkatan hasil belajar pada materi hukumhukum dasar kimia dan stoikiometri dengan menggunakan media pembelajaran multimedia presentasi apabila mencapai indikator-indikator di bawah ini:

a) Nilai rata-rata kelas mencapai ketuntasan kriteria minimal belajar sebesar 70 .

\begin{tabular}{|c|c|c|c|c|}
\hline No & Kode Siswa & Pre-Test & Pos-Test & Keterangan \\
\hline 1 & S001 & 60,00 & 83,33 & Tuntas \\
\hline 2 & S002 & 50,00 & 73,33 & Tuntas \\
\hline 3 & S003 & 33,33 & 66,67 & Tidak Tuntas \\
\hline 4 & S004 & 30,00 & 66,67 & Tidak Tuntas \\
\hline 5 & S005 & 36,67 & 53,33 & Tidak Tuntas \\
\hline 6 & S006 & 63,33 & 93,33 & Tuntas \\
\hline 7 & S007 & 46,67 & 86,67 & Tuntas \\
\hline 8 & S008 & 33,33 & 73,33 & Tuntas \\
\hline 9 & S009 & 36,67 & 66,67 & Tidak Tuntas \\
\hline 10 & S010 & 60,00 & 80,00 & Tuntas \\
\hline 11 & S011 & 33,33 & 76,67 & Tuntas \\
\hline 12 & S012 & 50,00 & 73,33 & Tuntas \\
\hline 13 & S013 & 30,00 & 53,33 & Tidak Tuntas \\
\hline 14 & S014 & 33,33 & 66,67 & Tidak Tuntas \\
\hline 15 & S015 & 26,36 & 56,67 & Tidak Tuntas \\
\hline 16 & S016 & 23,00 & 46,67 & Tidak Tuntas \\
\hline 17 & S017 & 36,67 & 86,67 & Tuntas \\
\hline 18 & S018 & 50,00 & 80,00 & Tuntas \\
\hline 19 & S019 & 23,33 & 66,67 & Tidak Tuntas \\
\hline 20 & S020 & 26,67 & 63,33 & Tidak Tuntas \\
\hline 21 & S021 & 36,67 & 70,00 & Tuntas \\
\hline 22 & S022 & 30,00 & 66,67 & Tidak Tuntas \\
\hline
\end{tabular}

b) Siswa mencapai ketuntasan kriteria minimal belajar sebesar 70 sebanyak $80 \%$

\section{Hasil dan Pembahasan}

Penelitian Tindakan Kelas ini menggunakan tahapan 2 siklus dan didapatkan hasil sebagai berikut:

\section{Siklus I}

Tabel 3. Hasil siklus I

JURNAL ILMIAH KOMPUTER GRAFIS Vol. 13, No. 1, Juli 2020 : 28 - 38 
p-ISSN : 1979-0414 e-ISSN : 2621-6256

\begin{tabular}{|l|l|l|l|l|}
23 & S023 & 33,33 & 73,33 & Tuntas \\
\hline 24 & S024 & 36,67 & 76,67 & Tuntas \\
\hline 25 & S025 & 30,00 & 66,67 & Tidak Tuntas \\
\hline 26 & S026 & 26,67 & 63,33 & Tidak Tuntas \\
\hline 27 & S027 & 50,00 & 80,00 & Tuntas \\
\hline 28 & S028 & 26,67 & 66,67 & Tidak Tuntas \\
\hline 29 & S029 & 23,33 & 50,00 & Tidak Tuntas \\
\hline 30 & S030 & 30,00 & 73,33 & Tuntas \\
\hline 31 & S031 & 26,67 & 56,67 & Tidak Tuntas \\
\hline 32 & S032 & 23,33 & 66,67 & Tidak Tuntas \\
\hline 33 & S033 & 40,00 & 80,00 & Tuntas \\
\hline 34 & S034 & 36,67 & 76,67 & Tuntas \\
\hline 35 & S035 & 33,33 & 71,00 & Tuntas \\
\hline 36 & S036 & 30,00 & 73,33 & Tuntas \\
\hline & Jumlah & 1296,03 & 2524,35 & \\
\hline & Rata-rata & 36,00083333 & 70,12083333 & \\
\hline
\end{tabular}

Dari tabel 3 diatas, maka :

Perhitungan rata-rata hasil belajar

Rata-rata $=\frac{\text { TotalKeseluruhan }}{\text { JumlahSiswa }}$

Rata-rata $=\frac{2524,35}{36}$

Rata-rata $=70,12$

\section{Perhitungan persentase ketuntasan kelas}

$\begin{array}{ll}\text { Rata-rata }= & \frac{\text { JumlahSiswaTuntas }}{\text { JumlahSiswa }} \times 100 \% \\ \text { Rata-rata }=\frac{19}{36} \times 100 \%\end{array}$




\section{Prosentase Ketuntasan Kelas Siklus I}

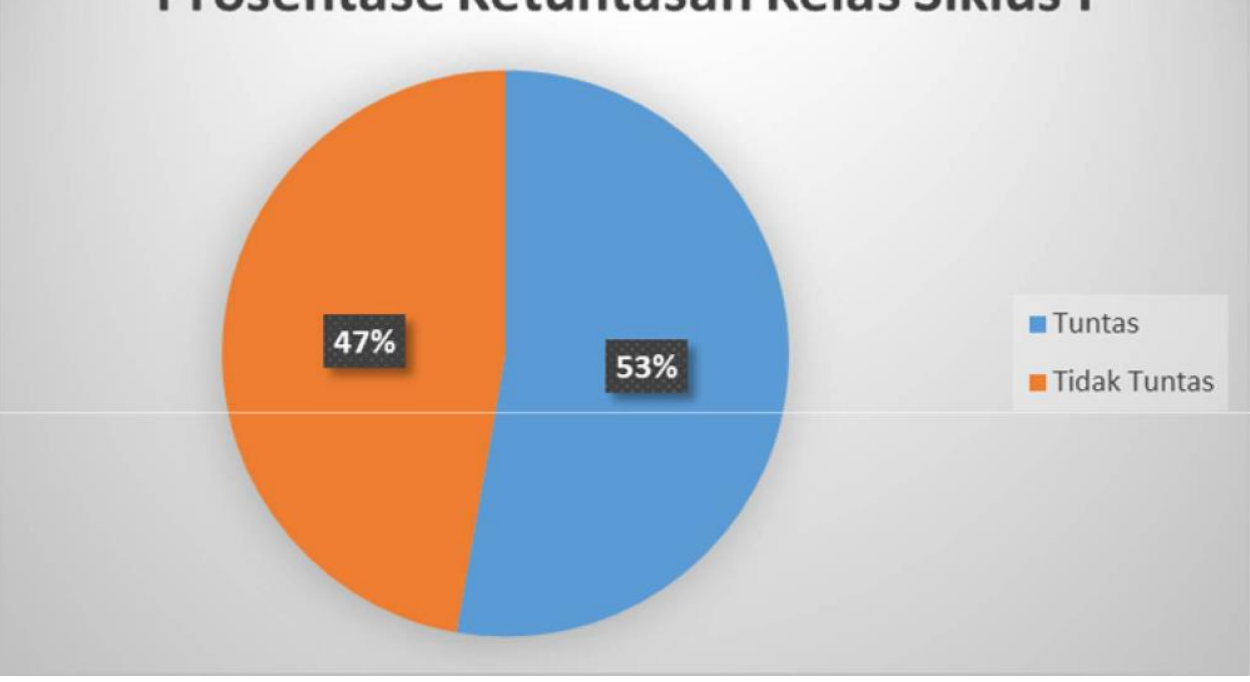

Gambar 3. Grafik ketuntasan siklus I

Gambar 3 menunjukkan bahwa prosentase tuntas hanya mencapai 53\% sehingga perlu dilakukan intervensi tindakan Siklus II.

\section{Siklus II}

Tabel 4. Hasil Siklus II

\begin{tabular}{|r|c|c|c|c|}
\hline \multicolumn{1}{|c|}{ No } & Kode Siswa & Pre-Test & Pos-Test & Keterangan \\
\hline 1 & S001 & 60,00 & 96,67 & Tuntas \\
\hline 2 & S002 & 50,00 & 90,00 & Tuntas \\
\hline 3 & S003 & 33,33 & 73,33 & Tuntas \\
\hline 4 & S004 & 30,00 & 76,67 & Tuntas \\
\hline 5 & S005 & 36,67 & 67,67 & Tidak Tuntas \\
\hline 6 & S006 & 63,33 & 100,00 & Tuntas \\
\hline 7 & S007 & 46,67 & 93,33 & Tuntas \\
\hline 8 & S008 & 33,33 & 86,67 & Tuntas \\
\hline 9 & S009 & 36,67 & 73,33 & Tuntas \\
\hline 10 & S010 & 60,00 & 86,67 & Tuntas \\
\hline 11 & S011 & 33,33 & 80,00 & Tuntas \\
\hline 12 & S012 & 50,00 & 83,33 & Tuntas \\
\hline 13 & S013 & 30,00 & 66,67 & Tidak Tuntas \\
\hline 14 & S014 & 33,33 & 73,33 & Tuntas \\
\hline 15 & S015 & 26,36 & 70,00 & Tuntas \\
\hline 16 & S016 & 23,00 & 66,67 & Tidak Tuntas \\
\hline 17 & S017 & 36,67 & 93,33 & Tuntas \\
\hline 18 & S018 & 50,00 & 86,67 & Tuntas \\
\hline 19 & S019 & 23,33 & 76,67 & Tuntas \\
\hline 20 & S020 & 26,67 & 70,00 & Tuntas \\
\hline
\end{tabular}

JURNAL ILMIAH KOMPUTER GRAFIS Vol. 13, No. 1, Juli 2020 : $28-38$ 
p-ISSN : $1979-0414$ e-ISSN : 2621-6256

\begin{tabular}{|l|l|l|l|l|}
21 & S021 & 36,67 & 76,67 & Tuntas \\
\hline 22 & S022 & 30,00 & 73,33 & Tuntas \\
\hline 23 & S023 & 33,33 & 73,33 & Tuntas \\
\hline 24 & S024 & 36,67 & 80,00 & Tuntas \\
\hline 25 & S025 & 30,00 & 70,00 & Tuntas \\
\hline 26 & S026 & 26,67 & 73,33 & Tuntas \\
\hline 27 & S027 & 50,00 & 86,67 & Tuntas \\
\hline 28 & S028 & 26,67 & 73,33 & Tuntas \\
\hline 29 & S029 & 23,33 & 67,67 & Tidak Tuntas \\
\hline 30 & S030 & 30,00 & 76,67 & Tuntas \\
\hline 31 & S031 & 26,67 & 70,00 & Tuntas \\
\hline 32 & S032 & 23,33 & 73,33 & Tuntas \\
\hline 33 & S033 & 40,00 & 86,67 & Tuntas \\
\hline 34 & S034 & 36,67 & 80,00 & Tuntas \\
\hline 35 & S035 & 33,33 & 67,77 & Tidak Tuntas \\
\hline 36 & S036 & 30,00 & 86,67 & Tuntas \\
\hline & Jumlah & 1296,03 & 2826,45 & \\
\hline & Rata-rata & 36,00083333 & 78,5125 & \\
\hline
\end{tabular}

Dari tabel 4 diatas, maka:

\section{Perhitungan rata-rata hasil belajar (SIKLUS II)}

$\begin{aligned} & \text { Rata-rata }=\frac{\text { TotalKeseluruhan }}{\text { JumlahSiswa }} \\ & \text { Rata-rata }= \begin{array}{l}2826,45 \\ \text { Rata-rata }=\end{array} \\ & 78,51\end{aligned}$

\section{Perhitungan persentase ketuntasan kelas (SIKLUS II)}

$\begin{array}{lll}\text { Rata-rata }= & \text { JumlahSiswaTuntas } & \\ \text { RumlahSiswa } & \times 100 \% \\ \text { Rata-rata }= & 31 & \\ \text { Rata-rata }= & 86,11 & \end{array}$




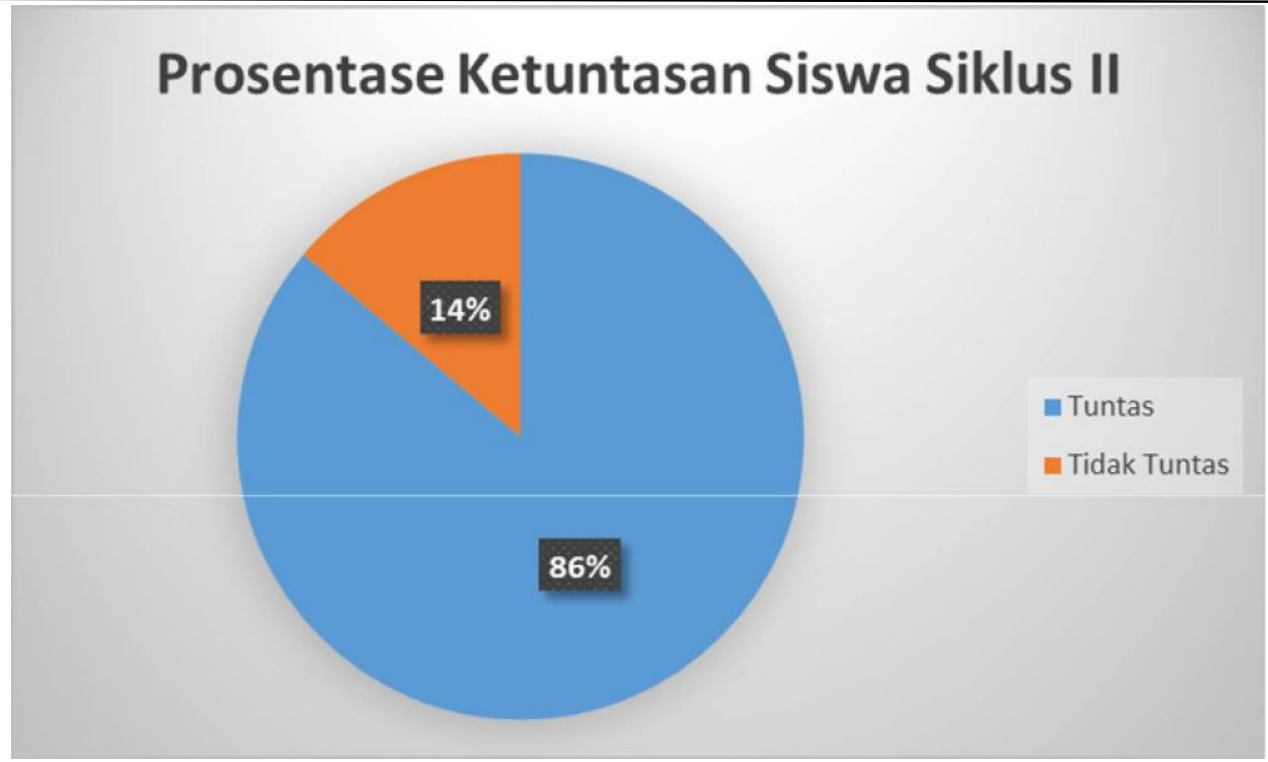

Gambar 4 Grafik ketuntasan siswa siklus II

Gambar 4 menunjukkan bahwa prosentase tuntas mencapai 86\%, artinya hasil intervensi tindakan kelas telah sesuai dengan yang diharapkan

\section{Simpulan dan Saran}

\section{Simpulan}

Berdasarkan hasil penelitian yang dilakukan kepada siswa kelas X MIPA 4 MAN 1 Grobogan, penerapan media pembelajaran multimedia presentasi pada materi hukum-hukum dasar kimia dan stoikiometri dengan konsep enjoyfull learning dapat meningkatkan hasil belajar siswa. Hal ini dapat ditunjukkan dengan ratarata tes hasil belajar siswa pada siklus I sebesar 70,12 dengan jumlah ketuntasan kelas sebesar 53,00\%. Kemudian nilai rata-rata hasil belajar siswa meningkat menjadi 78,51 dengan jumlah ketuntasan kelas sebesar $86,11 \%$ pada siklus II. Dengan demikian, maka dapat dikatakan bahwa penerapan media pembelajaran multimedia presentasi dapat meningkatkan hasil belajar kimia siswa khususnya pada materi hukum-hukum dasar kimia dan stoikiometri

\section{Saran}

Berdasarkan penelitian yang telah dilakukan, maka peneliti menyarankan:

1) Penggunaan media pembelajaran multimedia presentasi dalam pembelajaran kimia, khususnya untuk mempermudah pemahaman siswa dalam mempelajari hukum-hukum dasar kimia dan stoikiometri dapat dipertimbangkan oleh guru.

2) Agar penerapan media pembelajaran multimedia presentasi maksimal, sebaiknya guru memperhatikan karakteristik siswa dan materi pembelajarannya.

3) Guru diharapkan melaksanakan penelitian tindakan kelas untuk meningkatkan kinerjanya dalam memberikan pelayanan pendidikan sehingga menjadi guru yang profesional.

\section{Daftar Pustaka}

[1] Inanna. (2018). Peran Pendidikan dalam Membangun Karakter Bangsa yang Bermoral. JekpendJurnal Ekonomi dan Pendidikan, 1(1), 27-33. doi:10.26858/jekpend.v1i1.5057

[2] Jumadil, Gonggo, S. T., \& S. R. (2013). Peningkatan Hasil Belajar Kimia Menggunakan Multimedia Pada Materi Ikatan Kimia Kelas X SMK Negeri Parigi Selatan. Jurnal Akademia Kimia, 2(1), 39-46

[3] Hanum, L., Ismayani, A., \& Rahmi, R. (2017). Pengembangan Media Pembelajaran Buletin Pada Materi Hukum-Hukum Dasar Kimia Kelas X SMA/MA di Banda Aceh. Jurnal IPA dan Pembelajaran IPA (JIPI), 1(1), 42-48. Diambil kembali dari www. jurnal.unsyiah.ac.id/jipi

JURNAL ILMIAH KOMPUTER GRAFIS Vol. 13, No. 1, Juli 2020 : 28 - 38 
[4] Luthfi, A., Rachman, F. A., \& Ibrahim, A. R. (2014). Peningkatan Hasil Belajar Kimia Siswa SMAN 1 Indralaya di Kelas XI IPA 1 dengan Menerapkan Model Pembelajaran Kooperatif Tipe JIGSAW II. Jurnal Penelitian dan Pendidikan Kimia (JPPK), 1(2), 98-114. Diambil kembali dari https://ejournal.unsri.ac.id/index.php/jurpenkim

[5] Juliati, N., \& Rafiqah. (2017). Efektivitas Penerapan Metode Enjoyfull Learning dalam Peningkatan Minat Belajar Siswa Kelas X SMA Negeri 1 Bolo Kab. Bima. Jurnal Pendidikan Fisika, 5(1), 66-69. Diambil kembali dari http://journal.uinalauddin.ac.id/indeks.php/PendidikanFisika

[6] Nugroho, F., Mulyaningsih, I., \& Khuzaemah, E. (2019). Model Joyfull Learning Dalam Meningkatkan Ketrampilan Menulis Naskah Drama Siswa Kelas VIII. DEIKSIS, 11(3), 234243. doi:10.30998/deiksis.v11i03.3762

[7] Kurniawati, D., Masykuri, M., \& Saputro, S. (2016). Penerapan Model Pembelajaran Inkuiri Terbimbing Dilengkapi LKS untuk Meningkatkan Keterampilan Proses Sains dan Prestasi Belajar pada Materi Pokok Hukum Dasar Kimia Siswa Kelas X MIA 4 SMA N 1 Karanganyar Tahun Pelajaran 2014/2015. Jurnal Pendidikan Kimia (JPK), 5(1), 88-95. Diambil kembali dari http://jurnal.fkip.uns.ac.id/index.php/kimia

[8] Djumarah, \& Zain. (2007). Strategi Belajar Mengajar. Jakarta: Bhineka Cipta

[9] Anggoro, S. (2014). Pendekatan Joyfull Learning pada Proses Pembelajaran di Sekolah Dasar (Kajian Teoritis dan Neurosains). ResearchGate, 1-10.

[10] Fitrianingtyas, A. (2017). Peningkatan Hasil Belajar IPA Melalui Model Discovery Learning Siswa Kelas IV SDN Gedanganak 02. e-jurnal mitra pendidikan, 1(6), 709-720. Diambil kembali dari http://e-jurnalmitrapendidikan.com/index.php/e-jmp

[11] Sanjaya, W. (2010). Penelitian Tindakan Kelas. Jakarta: Kencana Prenada Media Group

[12] Badrujaman, A., \& Rahmat, D. (2010). Penelitian Tindakan Kelas. Jakarta: Trans Info Media.

[13] Gunarti, D. (2013). Penggunaan Media Pembelajaran "Mutimedia Presentasi" untuk Meningkatkan Hasil Belajar Siswa pada Materi Atom Karbon dan Senyawa Hidrokarbon. Jakarta: Universitas Syarif Hidayatullah.

[14] Ilahi, T. A., Sukartingsih, W., \& Subroto, W. T. (2018). Pengembangan Multimedia Interaktif Pada Pembelajaran Materi Jenis-jenis Pekerjaan untuk Meningkatkan Kemampuan Berfikir Kritis. Jurnal Review Pendidikan Dasar, 4(3), 1-10. Diambil kembali dari http://journal.unesa.ac.id/index.php/PD

[15] Kurniawati, I. D., \& NIta, S. (2018). Media Pembelajaran Multimedia Interaktif untuk Meningkatkan Pemahaman Konsep Mahasiswa. Journal of Computer and Information Technology, 1(2), 68-75. Diambil kembali dari http://ejournal.unipma.ac.id/index.php/doubleclick

[16] Pratama, D. R. (2013). Efektifitas Model Pembelajaran Generatif Berfasilitas Multimedia Learning Terhadap Hasil Belajar Siswa SMA Negeri 1 Ungaran. Semarang: Universitas Negeri Semarang. 